\title{
3 Research Square
Predictive Factors of Severe Abdominal Injuries Due to Seatbelt Compression in Motor Vehicle Passengers
}

\section{Kiyoshi lkegami}

Department of Legal Medicine, Shiga University of Medical Science

Masahito Hitosugi ( $\nabla$ hitosugi@belle.shiga-med.ac.jp)

Department of Legal Medicine, Shiga University of Medical Science

Kohei Takashima

Department of Legal Medicine, Shiga University of Medical Science

Yuki Sugitani

Department of Legal Medicine, Shiga University of Medical Science

Hitoshi Ida

Toyoda Gosei (Japan)

Masashi Aoki

Toyoda Gosei (Japan)

Michihisa Asaoka

Toyoda Gosei (Japan)

\section{Research Article}

Keywords:

Posted Date: March 7th, 2022

DOI: https://doi.org/10.21203/rs.3.rs-1343141/v1

License: (a) This work is licensed under a Creative Commons Attribution 4.0 International License. Read Full License 


\section{Abstract}

The data set of the National Automotive Sampling System/Crashworthiness Data System was retrospectively analyzed to clarify the pattern and severity of seatbelt-induced abdominal injuries and determine the predictive factors of severe abdominal injuries. Among data of collisions that occurred from 1995 to 2011, we chose front-seat passengers with a height of $>140 \mathrm{~cm}$ who developed seatbeltinduced abdominal injuries with an Abbreviated Injury Scale score of $\geq 2$ during a frontal collision. The study population comprised 79 persons ( 24 male, 55 female; mean age, 37.5 years) with 136 abdominal injuries. Spleen, kidney, and liver injuries were the three most common seatbelt-induced injuries. The spleen was the most commonly injured site in both the moderate and severe injury groups. The liver was the second most commonly injured site in the moderate injury group, but no liver injuries occurred in the severe injury group $(p=0.001)$. The multivariable logistic regression analysis revealed that force to the lower abdomen positively influenced the occurrence of severe injuries and that airbag deployment negatively influenced the occurrence of severe injuries. Correct seatbelt use and airbag deployment can prevent severe seatbelt-induced abdominal injuries. Physicians should still suspect moderate abdominal injuries even in correctly restrained vehicle passengers.

\section{Introduction}

The number of motor vehicle collisions (MVCs) has been continuously increasing worldwide, causing 1.35 million fatalities in 2016 [1]. MVCs are predicted to be an even bigger problem by 2030, by which time they will have become the fifth most common cause of fatalities globally [1]. Most MVC-related fatalities involve the death of vehicle passengers, accounting for $29 \%$ of MVC-related deaths worldwide [1]. Therefore, preventing fatalities and severe injuries of vehicle passengers is a priority for traffic safety.

Seatbelts are major safety devices, and their correct use is legally required in many countries. The effect of seatbelt use has been scientifically confirmed. A study in the United States suggested that use of a lapshoulder seatbelt decreased fatality by $72 \%$ [2]. Another study in the United States revealed that use of a seatbelt reduced mortality by $51 \%$ [3]. According to a Canadian study, a $1 \%$ increase in the use of seatbelts was associated with a $0.17-0.21 \%$ reduction in fatality [4]. Therefore, failure to use a seatbelt is a major risk factor for road traffic deaths among vehicle occupants. However, incorrect seatbelt use has also been associated with some adverse outcomes. Severe and even fatal deceleration injuries can occur as a result of incorrectly used seatbelts [5]. Lap belts have caused abdominal, pelvic, or spinal injuries because of their incorrect belt path. Shoulder belts produce a high local load, resulting in large chest deflection. In such cases, rib fractures and upper abdominal organ or digestive tract injuries have occurred. Intra-abdominal injuries may occur when a lap belt is not placed below the bilateral anterior superior iliac spines, instead crossing and compressing the abdomen. At the time of collision, the body slides below the belt, acting like a hinge; this has been called the submarine effect. Weaver et al. [6] suggested that at the time of frontal impact at a velocity of $56 \mathrm{~km} / \mathrm{h}, 3.4 \%$ of passengers sustained abdominal injuries with an Abbreviated Injury Scale (AIS) score of $\geq 2$ and $1.4 \%$ had an AIS score of $\geq 3$. Because injuries with an AIS score of $\geq 3$ are considered severe injuries that may lead to serious 
outcomes, preventing seatbelt-induced severe injuries is required to promote passengers' safety. Although several reports have described seatbelt-induced moderate and severe abdominal injuries, factors associated with the occurrence of severe abdominal injuries were not examined [7-16].

The objectives of this study were to clarify the pattern and severity of seatbelt-induced abdominal injuries using real-world accident data and to determine the predictive factors of severe abdominal injuries.

\section{Materials And Methods}

\section{Study design and patient selection}

We performed a retrospective analysis using the data set of the National Automotive Sampling System/Crashworthiness Data System (NASS/CDS). The NASS/CDS is generated by the United States National Highway Traffic Safety Administration. This is a publicly available, de-identified data set that provides data for approximately 5000 collisions every year. The database includes collisions in which at least one of the vehicles involved was damaged and had to be towed from the scene. The data in each case were collected from interviews with the people involved, police records, medical records, vehicle inspection, and scene inspection.

This database has been open to the public and anyone can access it. Because of the anonymous and retrospective nature of this study, the requirements for informed consent or approval by an institutional ethics committee were waived. We confirmed that all experiments were performed in accordance with relevant guidelines and regulations.

Among the individuals registered in the NASS/CDS from 1995 to 2011, the data of 5280 occupants whose height was $>140 \mathrm{~cm}$ in the front passenger seat of a passenger vehicle or commercial vehicle involved in a frontal vehicle collision were extracted. In this study, frontal collision was defined as an impact in the direction from the 11- to 1-o'clock position as viewed from above the vehicle. Because the seatbelt system in use at the time of the study was considered safe for passengers with a height of $\geq$ $140 \mathrm{~cm}$, we limited the passengers to those with this height range. After reviewing the use of seatbelts, 3596 persons who used a lap and shoulder belt were selected. Finally, we chose those persons who sustained seatbelt-related abdominal injuries with an AIS score of $\geq 2$. The final study population comprised 79 persons with 136 abdominal injuries (Fig. 1).

\section{Data collection}

The following information was collected from the database for each person involved in a collision:

(1) General characteristics including sex, age, height, weight, and body mass index (BMI)

(2) Airbag deployment 
(3) Collision velocity described using the equivalent barrier velocity (EBV). The EBV of the involved vehicles was calculated from the damage measurements and the known weight of the vehicles.

(4) Body position when forces were applied

(5) Type and severity of each injury sustained by the occupant, described using the AIS score. The AIS score is used to categorize the injury type and anatomical severity in each body region using a scale from 1 (minor) to 6 (clinically untreatable) [17]. Injuries with an AIS score of 2 were defined as moderate, and those with an AIS score of $\geq 3$ were defined as severe. The maximum AIS was defined as the highest AIS score.

\section{Statistical analysis}

Categorical variables are summarized in the form of a numerical value with proportion or frequency. Continuous variables are summarized as mean \pm standard deviation for values that followed a normal distribution. The chi-square test was used to compare prevalence between the two groups. Student's t-test was used to identify differences in values between the groups. A multivariable logistic regression analysis was performed to determine which variables were independently associated with severe injuries. We applied the Hosmer-Lemeshow test to determine the goodness-of-fit of the regression models (higher probability indicates better fit). Additionally, we calculated pseudo $R^{2}$ (Nagelkerke's $R^{2}$ ) as an index of the degree of proportion explainable by the regression equation (a larger $\mathrm{R}^{2}$ indicates a better model). The statistical analyses were performed with IBM SPSS version 23 (IBM Corp., Armonk, NY, USA). A p value of $<0.05$ was considered statistically significant.

\section{Results}

\section{General characteristics}

The 79 persons analyzed in this study comprised 24 male and 55 female individuals. Their mean age was $37.5 \pm 22.3$ years (range, $7-88$ years). Their mean height was $165.4 \pm 10.5 \mathrm{~cm}$ (range, $140-196 \mathrm{~cm}$ ), mean weight was $67.4 \pm 16.0 \mathrm{~kg}$ (range, $32-113 \mathrm{~kg}$ ), and mean BMI was $24.6 \pm 5.3 \mathrm{~kg} / \mathrm{m}^{2}$ (range, 13.9 $36.8 \mathrm{~kg} / \mathrm{m}^{2}$ ). Their mean EBV at the time of the collision was $45.2 \pm 15.9 \mathrm{~km} / \mathrm{h}$ (range, $12-91 \mathrm{~km} / \mathrm{h}$ ), and an airbag was deployed in the vehicles of 39 passengers.

The distribution of the 136 injury sites is shown in Table 1. The spleen was the most commonly injured site, followed by the kidneys, liver, and mesentery. Because the liver, gallbladder, spleen, stomach, duodenum, omentum, and pancreas are located in the upper abdomen, these injuries were considered to have been caused by forces applied to the upper abdomen. Other injuries were considered to have been caused by forces applied to the lower abdomen. Excluding the category "others," forces applied to the upper abdomen caused 71 injuries and forces applied to the lower abdomen caused 62 injuries. 


\section{Comparison of passengers with moderate and severe injuries}

We created two data sets for the current study: passengers with moderate injuries (45 persons) and passengers with severe injuries (34 persons). First, we compared the basic characteristics between the two groups (Table 2). No significant differences were found in any items.

Next, the distribution of the injured sites was compared. In both groups, the spleen was the most commonly injured site. The liver was the second most commonly injured site among the passengers with moderate injuries, whereas no liver injuries occurred among the passengers with severe injuries $(p=$ 0.001) (Table 3).

\section{Factors associated with severe injuries}

To identify the variables that were independently associated with the occurrence of severe injuries, we conducted a multivariate logistic regression analysis using the forced input method. The independent variables were age, sex (reference: male), BMI, airbag deployment (reference: no), EBV, and body region corresponding to the maximum AIS score (reference: upper abdomen). The results showed that a force to the lower abdomen positively influenced the occurrence of severe injuries (odds ratio, 3.507) and that airbag deployment negatively influenced the occurrence of severe injuries (odds ratio, 0.279) (Table 4). The Hosmer-Lemeshow test indicated a good fit $(p=0.341)$, and Nagelkerke's $R^{2}$ was 0.236 .

\section{Discussion}

A systematic review and meta-analysis of cohort studies revealed that the risk of any major injuries was significantly lower in seatbelt users than non-users with a relative risk of 0.47 [18]. Additionally, although statistical significance was obtained in the analyses of injuries in each body region, the relative risk for abdominal injuries (0.87) was higher than that for head (0.49), neck (0.69), and lower limb injuries (0.77) [18]. This fact is substantially due to seatbelt-induced abdominal injuries. A recent study based on nationwide hospital data suggested that the AIS score of the abdomen was the single significant influencing factor for fatalities of motor vehicle passengers [19]. The authors also suggested that seatbelt compression might somewhat contribute to the occurrence of abdominal organ injuries. Accordingly, that study was the first to show the actual situation of moderate and severe abdominal injuries due to compression by seatbelts.

In the present study, spleen, kidney, and liver injuries were the three most common injuries induced by seatbelts. This finding is in accordance with previous reports showing that the liver, spleen, and digestive system are the most frequently injured among all abdominal organs in frontal collisions [7, 8]; additionally, research has shown that seatbelts are associated with renal injuries and high odds of liver injuries $[9,10]$. Our study also revealed that the severity of all liver injuries was moderate and not severe. According to a large retrospective study, MVC-related liver injuries in patients who used a seatbelt with airbag deployment were the least likely to sustain severe injuries and/or death and had fewer 
complications, whereas patients with no protective device had the highest risk of these outcomes [11]. Our analysis also confirmed that seatbelt-induced liver injuries were not severe.

In this study, we confirmed that force applied to the lower abdomen was a positive predictor and that airbag deployment was a negative predictor of seatbelt-induced severe injuries. Forces to the lower abdomen were due to compression by lap belts with an incorrect belt path. Even if passengers basically use seatbelts correctly, errors sometimes occur. A recent study of seatbelt position among rear-seat passengers showed that the lap belt was placed above the correct position (on the anterior superior iliac spine) in $40 \%$ of male passengers [20]. Therefore, health-care professionals must advise patients on the proper use of seatbelts, with a lap belt fitting the ilium under the theory that inertial loads from the body interacting with the lap belt are distributed to a greater degree over the skeleton. Airbag deployment mitigates the seatbelt-induced forces by reducing forward movement. Although the frequency of mild injuries to the face or extremities has increased with the use of airbags, the forces to the abdomen have decreased by the distribution of blunt force energy away from the abdomen [21-24]. The purpose of a restraint system is to gradually decelerate the occupant over a longer period of time as well as distribute collision forces over a larger portion of the bony skeleton [25]. Therefore, airbag deployment in conjunction with correct seatbelt use can protect against severe abdominal injuries.

Collision velocity was not a predictive factor for seatbelt-induced severe injuries in the present study. However, according to a previous study, the vehicle velocity at impact was directly proportional to the severity of intra-abdominal organ injuries [12]. The study showed that a rise in the impact velocity from 40 to $50 \mathrm{~km} / \mathrm{h}$ led to a $2.8 \%$ higher rate of abdominal trauma and that a rise in the impact velocity from 40 to $70-79 \mathrm{~km} / \mathrm{h}$ led to a $24.6 \%$ higher rate of abdominal trauma [13]. The difference between this result and present result may be due to the difference in the collision velocity; our data showed lower collision velocities (the mean EBV in the moderate and severe injury groups was 36.2 and $43.9 \mathrm{~km} / \mathrm{h}$, respectively). Additionally, the BMI was not a predictive factor for severe injuries. According to a previous study based on a huge collision database, obese occupants had a higher incidence rate of belt placement superior to the anterior superior iliac spine than occupants with a normal BMl; however, there was no significant difference between the occupants' BMI and the incidence of abdominopelvic organ injuries [14]. Therefore, our result is in accordance with this previous study.

Seatbelt use during severe MVCs may result in the transmission of significant forces to the abdomen and chest instead of hard collision with the steering or instrument panel. A seatbelt sign is a linear skin discoloration suggesting subcutaneous hemorrhage by seatbelt compression during the collision. The presence of a seatbelt sign on the abdomen implies a significant impact and transfer of kinetic energy to the abdominal wall. One study suggested that up to $10 \%$ of MVC passengers with a seatbelt sign had an underlying hollow viscus injury [15]. Another study showed that among patients with a seatbelt sign, twothirds had an underlying bowel injury [16]. However, a recent retrospective cohort study revealed no association between a seatbelt sign and the occurrence of intra-abdominopelvic injuries [13]. Therefore, in spite of the seatbelt sign, physicians should still suspect seatbelt-induced injuries especially in the lower abdomen of restrained passengers without deployment of an airbag. 
This study had some limitations. First, the data used in this study were extracted from collisions that occurred from 1995 to 2011; more recent data were not obtained. Therefore, the safety systems of the vehicles in our study may have differed from those currently in use. However, the results show the basic trends and information concerning seatbelt-induced severe abdominal injuries. When similar studies using recently obtained collision data are performed in future, they may reveal changes in the prevalence and characteristics of seatbelt-induced abdominal injuries based on the present results. Second, we used a United States vehicle collision database in this study. Because of the worldwide variations in traffic situations and collision characteristics, such as passenger body size, vehicle size, and speed limits, the present findings may not be generalizable to all countries. Additional research using data from international sources is required. Third, because we chose vehicle passengers who had injuries with AIS scores of $>1$, we did not identify mild injuries induced by seatbelts. However, because the objective of this study was to elucidate the characteristics and predictive factors of seatbelt-induced severe injuries, this issue might not have influenced the present results. Further research including all seatbelt-induced injuries is required to improve safety for vehicle passengers.

\section{Conclusions}

According to this retrospective analysis of the NASS/CDS database, spleen, kidney, and liver injuries were the three most common abdominal injuries induced by seatbelts. The liver was the second most commonly injured site among patients with moderate injuries, whereas no liver injuries occurred among patients with severe injuries $(p=0.001)$. The multivariable logistic regression analysis revealed that force applied to the lower abdomen positively influenced the occurrence of severe injuries (odds ratio, 3.507) and that airbag deployment negatively influenced the occurrence of severe injuries (odds ratio, 0.279). Correct seatbelt use and airbag deployment can help to prevent severe abdominal injuries induced by seatbelts. Additionally, physicians should still suspect moderate abdominal injuries even in correctly restrained vehicle passengers.

\section{Declarations}

\section{Acknowledgment}

We thank Angela Morben, DVM, ELS, from Edanz (https://jp.edanz.com/ac) for editing a draft of this manuscript.

\section{Author contributions}

K.I. designed the study, analyzed the data, and drafted the manuscript.

M.H. designed the study and drafted the manuscript.

K.T. analyzed the data and performed the statistical analyses. 
H.I. acquired and analyzed the data.

M. Aoki acquired and analyzed the data.

M. Asaoka critically reviewed the work for important intellectual content.

\section{Competing interests}

The authors declare no competing interests.

\section{Data availability}

The data presented in this study are available from the corresponding author upon request.

\section{References}

1. World Health Organization. Global Status Report on Road Safety 2018. https://www.who.int/violence_injury_prevention/road_safety_status/2018/en/ (2018).

2. Crandall, C. S., Olson, L. M. \& Sklar, D. P. Mortality reduction with air bag and seat belt use in head-on passenger car collisions. Am J Epidemiol. 153, 219-224 (2001).

3. Cummins, J. S., Koval, K. J., Cantu, R. V. \& Spratt, K. F. Do seat belts and air bags reduce mortality and injury severity after car accidents? Am J Orthop (Belle Mead NJ). 40, E26-29 (2011).

4. Sen, A. \& Mizzen, B. Estimating the Impact of Seat Belt Use on Traffic Fatalities: Empirical Evidence from Canada. Can Public Policy. 33, 315-335 (2007).

5. Abbas, A. K., Hefny, A. F. \& Abu-Zidan, F. M. Seatbelts and road traffic collision injuries. World J Emerg Surg. 6, 18 (2011).

6. Weaver, A. A. et al. Estimated injury risk for specific injuries and body regions in frontal motor vehicle crashes. Traffic Inj Prev. 16 Suppl 1, S108-116 (2015).

7. Lamielle, S. et al. Abdominal injury patterns in real frontal crashes: influence of crash conditions, occupant seat and restraint systems. Annu Proc Assoc Adv Automot Med. 50, 109-124 (2006).

8. Rouhana, S. W., Ridella, S. A. \& Viano, D. C. The effect of limiting impact force on abdominal injury: a preliminary study. $30^{\text {th }}$ Stapp car crash conference proceeding, Warrendale, 65-79 (1986).

9. Bjurlin, M. A., Fantus, R. J., Fantus, R. J., Mellett, M. M. \& Villines, D. The impact of seat belts and airbags on high grade renal injuries and nephrectomy rate in motor vehicle collisions. J Urol. 192, 1131-1136 (2014).

10. Holbrook, T. L. et al. The impact of safety belt use on liver injuries in motor vehicle crashes: the importance of motor vehicle safety systems. J Trauma. 63, 300-306 (2007).

11. Renson, A., Musser, B., Schubert, F. D. \& Bjurlin, M. A. Seatbelt use is associated with lower risk of high-grade hepatic injury in motor vehicle crashes in a national sample. J Epidemiol Community Health. 72, 746-751 (2018). 
12. Lamielle, S. et al. Abdominal injury patterns in real frontal crashes: influence of crash conditions, occupant seat and restraint systems. Annu Proc Assoc Adv Automot Med. 50, 109-124 (2006).

13. Glover, J. M. et al. Association between seatbelt sign and internal injuries in the contemporary airbag era: A retrospective cohort study. Am J Emerg Med. 36, 545-550 (2018).

14. Schieffer, S. et al. The relationship of body mass index, belt placement, and abdominopelvic injuries in motor vehicle crashes: A Crash Injury Research and Engineering Network (CIREN) study. Traffic Inj Prev. 2021 Oct 18, 1-3; 10.1080/15389588.2021.1982596 (2021).

15. Allen, G. S. et al. Hollow visceral injury and blunt trauma. J Trauma. 45, 69-75 (1998).

16. Chandler, C. F., Lane, J. S. \& Waxman, K. S. Seatbelt sign following blunt trauma is associated with increased incidence of abdominal injury. Am Surg. 63, 885-888 (1997).

17. Association for the Advancement of Automotive Medicine. The abbreviated injury scale, 1990 revision. (Association for the Advancement of Automotive Medicine, 1990).

18. Fouda Mbarga, N., Abubakari, A. R., Aminde, L. N. \& Morgan, A. R. Seatbelt use and risk of major injuries sustained by vehicle occupants during motor-vehicle crashes: a systematic review and metaanalysis of cohort studies. BMC Public Health. 18, 1413; 10.1186/s12889-018-6280-1 (2018).

19. Ishii, W., Hitosugi, M., Takeda, A., Baba, M. \& lizuka, R. Factors influencing vehicle passenger fatality have changed over 10 years: a nationwide hospital-based study. Sci Rep. 10, 3316; 10.1038/s41598020-60222-z (2020).

20. Mizuno, K. et al. The Effects of Inboard Shoulder Belt and Lap Belt Loadings on Chest Deflection. Stapp Car Crash J. 62, 67-91 (2018).

21. Koisaari, T. et al. Airbag deployment-related eye injuries. Traffic Inj Prev. 18, 493-499 (2017).

22. Shields, R. A. \& Rachitskaya, A. Ocular trauma and airbag deployment. JAMA Ophthalmol. 132, 12451246 (2014).

23. Atkinson, P. et al. An under-hand steering wheel grasp produces significant injury risk to the upper extremity during airbag deployment. Annu Proc Assoc Adv Automot Med. 46, 45-62 (2002).

24. Jernigan, M. V. \& Duma, S. M. The effects of airbag deployment on severe upper extremity injuries in frontal automobile crashes. Am J Emerg Med. 21, 100-105 (2003).

25. Greenston, M., Wood, R. L. \& Reinhart, L. Clinical Significance of the Seat Belt Sign as Evidence of a Compromised Occupant-Seat Belt Relationship. J Emerg Med. 56, 624-632 (2019).

\section{Tables}


Table 1. Injuries distribution among all cases

\begin{tabular}{lc}
\hline Injury sites by the organ & $\mathrm{N}(\%)$ \\
\hline \hline Stomach & $1(0.7)$ \\
Duodenum & $5(3.7)$ \\
Omentum & $1(0.7)$ \\
Liver & $17(12.5)$ \\
Gallbladder & $1(0.7)$ \\
Spleen & $43(31.6)$ \\
Pancreas & $3(2.2)$ \\
Adrenal glands & $1(0.7)$ \\
Kidney & $23(16.9)$ \\
Abdominal aorta & $1(0.7)$ \\
Jejunum & $10(7.4)$ \\
Colon & $8(5.9)$ \\
Mesenterium & $16(11.8)$ \\
Retroperitoneum & $1(0.7)$ \\
Bladder & $1(0.7)$ \\
Rectum & $1(0.7)$ \\
Others & $3(2.2)$ \\
\hline
\end{tabular}

Table 2. Comparison of general characteristics between persons with moderate and severe iriuries

\begin{tabular}{|c|c|c|c|c|c|}
\hline & \multicolumn{2}{|c|}{$\begin{array}{c}\text { Moderate (AIS2) } \\
N=45\end{array}$} & \multicolumn{2}{|c|}{$\begin{array}{c}\text { Severe }(\text { AIS } 3+) \\
N=34\end{array}$} & \multirow[b]{2}{*}{$P$ Value } \\
\hline & Mean $=\mathrm{SD} / \mathrm{N}(\%)$ & Range & Mean $=\mathrm{SD} / \mathrm{N}(\%)$ & Range & \\
\hline \multicolumn{6}{|l|}{ Sex } \\
\hline Male & $15(33.3)$ & - & $9(26.5)$ & - & \\
\hline Femal & $30(66.7)$ & - & $25(73.5)$ & - & 0.51 \\
\hline Age (years) & $36.0=22.3$ & $7-84$ & $39.4=22.6$ & $8-84$ & 0.51 \\
\hline Height $(\mathrm{cm})$ & $166.1=9.9$ & $147-185$ & $164.4=11.4$ & $140-196$ & 0.87 \\
\hline Weight (kg) & $69.0=15.8$ & $41-106$ & $65.3=16.4$ & $32-113$ & 0.52 \\
\hline $\mathrm{BMI}\left(\mathrm{kg} \mathrm{m}^{2}\right)$ & $23.6=4.7$ & $13.9-36.7$ & $26.0=5.9$ & $15.4-36.8$ & 0.53 \\
\hline EBV $(\mathrm{km} / \mathrm{h})$ & $36.2=16.0$ & $18-91$ & $43.9=16.0$ & $12-73$ & 0.52 \\
\hline Airbag deployment & $26(57.8)$ & - & $13(38.2)$ & - & 0.08 \\
\hline
\end{tabular}

AIS, Abbreviated Injury Scale; SD, standard deviation; BMI, body mass index; EBV, equivalent barrier velocity 
Table 3. Comparison of prevalence of each injury between persons with moderate and severe iryuries

\begin{tabular}{lccc}
\hline & Moderate (AIS2) & Severe (AIS3+) & P V alue \\
\hline \hline Stomach & $\mathrm{N}=91$ & $\mathrm{~N}=45$ & 0.15 \\
Duodenum & $0(0)$ & $1(2.2)$ & 0.74 \\
Omentum & $3(3.3)$ & $2(4.4)$ & 0.48 \\
Liver & $1(1.1)$ & $0(0)$ & 0.001 \\
Gallbla dder & $17(18.7)$ & $0(0)$ & 0.61 \\
Spleen & $1(1.1)$ & $0(0)$ & 0.49 \\
Pancreas & $27(29.7)$ & $16(35.6)$ & 0.99 \\
Adrenal glands & $2(2.2)$ & $1(2.2)$ & 0.15 \\
Kidney & $0(0)$ & $1(2.2)$ & 0.77 \\
Abdominal aorta & $16(17.6)$ & $7(15.6)$ & 0.15 \\
Jejunum & $0(0)$ & $1(2.2)$ & 0.45 \\
Colon & $5(5.5)$ & $5(11.1)$ & 0.62 \\
Mesenterium & $6(6.6)$ & $2(4.4)$ & 0.45 \\
Retroperitoneum & $12(13.2)$ & $4(8.9)$ & 0.15 \\
Bladder & $0(0)$ & $1(2.2)$ & 0.48 \\
Rectum & $1(1.1)$ & $0(0)$ & 0.15 \\
Others & $0(0)$ & $1(2.2)$ & 0.13 \\
\hline & $0(0)$ & & \\
\hline
\end{tabular}

AIS, Abbreviated Injury Scale

Table 4. Results of multivariate logistic regression analysis

\begin{tabular}{lccc}
\hline Independent variable & Coeficient & OR $(95 \% \mathrm{CD})$ & $P$ Vahe \\
\hline \hline EBV & -0.004 & $0.996(0.964-1.03)$ & 0.83 \\
Age & 0.008 & $1.008(0.982-1.035)$ & 0.56 \\
Airbag deployment (Ref. No) & -1.275 & $0.279(0.09-0.868)$ & 0.03 \\
Sex (Ref Male) & 0.71 & $2.034(0.604-6.848)$ & 0.25 \\
BM & 0.051 & $1.052(0.942-1.175)$ & 0.37 \\
Bodyregion corresponding to MAIS (Ref. upper abdomen) & 1.255 & $3.507(1.313-9.363)$ & 0.01 \\
\hline
\end{tabular}

$\mathrm{OR}$, odds ratio; $\mathrm{Cl}$, confidence interval; $\mathrm{EBV}$, equivalent barrier velocity; $\mathrm{BMI}$, body mass index; MAIS, maximum Abbreviated Injury Scale 
Figures

\section{Figure 1}

Flowchart of enrollment in the study 